Irish Journal of Psychological Medicine 1996 December; 13 (4): 170-1

\section{Litigation and the toxicity of psychotropic drugs: A reply to Prof Patricia Casey}

Sir - I was somewhat surprised to read Professor Casey's response to my editorial on Litigation and the toxicity of psychotropic drugs that was published in the September issue of the Journal. ${ }^{1,2}$ I had assumed that all of us dealing with the treatment of mental illness, whether practising clinicians or laboratory based psychopharmacologists, had a common task to ensure that patients received the best possible drug treatment irrespective of the cost. Clearly Professor Casey's view differs substantially from mine regarding the safety, tolerability and ultimately the effect for the quality of life of the depressed patient who receives one of the second generation antidepressants (of which the selective serotonin reuptake inhibitor represent one of many types) rather than a first generation tricyclic antidepressant.

In her commentary, ${ }^{2}$ Professor Casey raised several points. Clearly a key issue in the debate on suicide prevention is the extent to which suicide rates are affected by the availability of means to commit suicide. In a recent publication from Sweden, Carlsten $e t a l^{3}$ analysed the changes in the rates of suicide by poisoning, between 1979 and 1992 . There was a decrease in the suicide rate during the 1970s which was directly associated with the decrease in sales of barbiturates. However, the prescription of analgesics and antidepressants increased during the study period as did the rates of suicide using these drugs. This confirms the study of Farmer in England and Wales, who reported that the majority of suicides by poisoning are now attributable to one of five products - paracetamol, dextroprophyxylphene, amitriptyline, dothiepin and temazepam, the deaths due to temazepam occurring when the drug was taken in combination with one of these tricyclic antidepressants or analgesics. Henry et al have recently shown that amitriptyline and dothiepin account for $80 \%$ of all deaths in the UK caused by overdose of antidepressants. When the suicide rates are related to the prescription volume, the order of toxicity is found to be tricyclic antidepressants (excluding lofepramine, which should be considered as a relatively non cardiotoxic second generation tricyclic antidepressant) $<$ non selective monoamine oxidase inhibition $<$ SSRIs and the other second generation tricyclic antidepressants. It is emphasised that general practitioners, who see approximately $60 \%$ of all suicide victims before their death, have a crucial role to play in prescribing antidepressants which are least likely to prove fatally toxic in overdose. This action should be considered of paramount importance in any campaign aimed at reducing the suicide rate.

Daly ${ }^{6}$ has addressed the medico-legal aspects of prescribing and emphasised that, with regard to providing reasonable care and precautions to a patient with major depression, a decision must be taken on the appropriateness of prescribing antidepressants which are lethal in overdose. Ethical and legal requirements require the clinician to obtain informed consent to treatment for the patient. In the case of the tricyclic antidepressants this would require a warning regarding their toxicity in overdose which, in the case of a suicidal patient, would seem negligent. Clearly there is a major difference in culpability in the case of a clinician who prescribes a cardiotoxic tricyclic antidepressant to a depressed patient who subsequently commits suicide by taking an overdose of that drug to the situation where, a noncardiotoxic SSRI is prescribed to a depressed patient who, later commits suicide by some other means.

With regard to the contribution of psychotropic drugs to road traffic accidents, Professor Casey is, of course, correct in stating that depressed patients are cognitively impaired. She is incorrect in stating that the sedative side effects of the tricyclic antidepressants obviate the need for anxiolytics. Double-blind, placebo controlled trials of the SSRIs and nefazodone in which amitriptyline or imipramine were used as comparator antidepressants, clearly show that the tricyclic antidepressants do not differ from placebo in attenuating the anxiety component whereas an SSRI or nefazodone is effective in this respect. Just because a patient is sedated by the antihistaminic action of a tricyclic antidepressant it cannot be concluded that the symptoms of anxiety are reduced. Furthermore as the tricyclic antidepressants have long halflives (in excess of 24 hours) the chances of daytime sedation and enhanced cognitive impairment are increased. The elderly depressed patient would suffer particularly from this effect.

Regarding the effect of psychotropic drugs on traffic accidents, a recent survey by de Gier, ${ }^{7}$ conducted under the auspices of the Directorate General for Transport of the EC, concluded that approximately $10 \%$ of the adult population of most EC countries is driving under the influence of cognitively impairing psychotropic drugs, which incur at least twice the risk of being involved in a road traffic accident. It is estimated that this accounts for 4,500 deaths, 135,000 injuries and 6.3 billion ECU damage to society per annum in the EC. To put this in perspective, $5 \%$ of drivers involved in road traffic accidents in the UK in 1994 were taking antidepressants (tricyclics) and 5\% benzodiazepines. Somewhat similar figures are quoted for other EU countries in western Europe. Ray et $a l^{8}$ has drawn similar conclusions of the effects of sedative antidepressants on road traffic accidents in elderly drivers in the USA.

Finally, Professor Casey queries the clinical relevance of the discontinuation rates from drug trails to the normal clinical setting. With all their limitations, at least the properly conducted double-blind placebo controlled trials against comparator tricyclic antidepressants have the clear advantage over uncontrolled, ancedotal and statistically insignificant cases seen by overworked clinicians in hospital or general practice!

The meta-analysis of 42 published randomised controlled studies comparing different SSRI with tricyclic antidepressants by Montgomery et al" showed that significantly fewer patients $(14.9 \%)$ discontinued treatment on SSRIs than tricyclics $(19 \%)$, an effect which was even more marked when compared to the placebo group. There was no difference between the SSRI and tricyclic treated groups regarding the drop-out rates due to lack of antidepressant efficacy. Clearly the risk benefit calculation favours the SSRIs. 
In conclusion, I would agree with Professor Casey that defensive medicine and kneejerk practice is no substitute for sound clinical judgement. Based on the scientific facts which are now available to the medical profession, I do question the objective basis of what she considers to be sound clinical judgement.

\section{Brian E Leonard, PhD, DSc, MRIA Professor of Pharmacology, Pharmacology Department, University College Galway, Co Galway Ireland.}

\section{References}

1. Leonard BE. Editorial: Litigation and the toxicity of psychotropic drugs. Ir J Psychol Med 1996; 13: 88-9

2. Casey P. Commentary: Litigation and the toxicity of psychotropic drugs. Ir J Psychol Med 1996; 13: 89-90

3. Carlston A, Allebeck P, Brandt L. Are suicide rates in Sweden associated with changes in the prescribing of medicines? Acta Psychiat Scand 1996; 94: 94-100.

4. Farmer RDT. Suicide and poisons. Human Psychopharmac 1994; 9(1): Sl-S21. 5. Henry JA, Alexander CA, Sener EK. Relative mortality from overdose of antidepressives. BMJ 1995; 310: 22 1-4.

6. Daly RJ. Medico-legal aspects of prescribing. Human Psychopharmac 1994; 9(1): S31-S36

7. de Gier JJ. Drugs other than alcohol and driving in the European Union. Study coordinated with the support of the European Blood Safety Federation and the Directorate General for Transport of the Commission for the European Communities. EC document 1995; IHP: 95-94.

8. Ray WA, Fought RL, Decker MD. Psychoactive drugs and the risk of injurious motor vehicle crashes in elderly drivers. Am J Epidemiol 1992; 16: 873-83.

9. Montgomery SA, Henry JA, McDonald G, et al. Selective serotonin re-uptake inhibitors: meta analysis of discontinuation rates. Int Clin Psychopharmac 1994; 9: 47-53.

\section{Dysmnesic MCQs}

Sir - An experienced neurologist reported great difficulty in finding the correct answers to neurological MCQ questions when these were requested by the first author whilst he was preparing for the College exams. Experienced psychiatrists often have the same experience when attempting to answer psychiatric MCQ questions for their trainees. The basic problem was illustrated when the second author sought guidance with this question' $-Q(28)$. "Following a head injury, the following is true: - Anterograde amnesia may persist for longer than post-traumatic amnesia." The answer, "true".

The correct answer is that it is controversial and misleading. The question was derived from Kopelman ${ }^{2}-$ "post-traumatic amnesia (PTA) refers to memory loss for events following a lesion. Anterograde amnesia (AA) refers to an impairment in learning new material. AA, may persist long after the termination of PTA." These definitions are uncomfortably alike for clinical purposes, as Kopelman agrees when he writes: "AA is commonly used synonymously with PTA."'2

Varying definitions abound, eg. one source defines PTA in terms of memory and AA in terms of conscious level. The problem would be solved if we had only the following terms; post-traumatic disturbance of consciousness (PTDC) and PTA, each meaning what they said. Unless terminology reflects what is being observed it is dangerously misleading. How many trainees can remember the difference between hypnagogic and hypnopompic hallucinations before they see the go (- ing to sleep) in hypnagogic?

\section{Brian O'Shea, MB, BCh, FRCPsych, Consultant Psychiatrist Rita Condren, $\mathrm{MB}, \mathrm{BCh}$, Senior House Officer, Newcastle Hospital, Greystones, Co Wicklow, Ireland.}

References

1. Green B. The MRCPsych Study Manual. Dordrecht, The Netherlands: Kluwer Academic Publications, 1993.

2. Kopelman MD. Amnesia: organic and psychogenic. Br J Psychiatry 1987; 150: 428-42.

3. Gelder M, Gath D, Xayou R, Cowen P. Oxford Textbook of Psychiatry, 3rd ed. Oxford: Oxford University Press, 1996.

\section{Psychiatric inpatient suicide}

Sir - Coakley et al in their thoughtful study of inpatient suicides ${ }^{1}$ recommend two types of investigation following an inpatient suicide; a formal inquiry and a confidential informal review of the event. I have worked in a system where such a practice has been in place for many years and I support their recommendations in this regard.

When a suicide occurs in either the inpatient or outpatient setting a procedure known as a "Psychological Autopsy" is activated. Administrative and clinical staff who have been involved in any way with the patient, as well as care givers from the community are invited to review the deceased patient's contact with our services, the treatment strategies that were used, and make recommendations to prevent a similar tragedy. A record which is kept confidential within the department is kept of the recommendations. This procedure serves as a healing ritual for staff and helps protect staff morale. It helps to deal with the feelings of loss and grief that many staff experience when the tragedy of a suicide occurs.

Dr Patrick G Coll, MB, FRCP (C) Clinical Assistant Professor, Department of Psychiatry, University of Calgary, Calgary General Hospital, 841 Centre Ave East, Calgary, Alberta T2E OAI, Canada.

Reference

1. Coakley GM, Carey TG, Owens JM. A study of psychiatric inpatient suicides. Ir J Psychol Med 1996; 13(3): 102-4 